\title{
ANALISIS KEPUTUSAN PEMBELIAN KONSUMEN DI TOKO TRADISIONAL DALAM MENGHADAPI PERTUMBUHAN RITEL MODERN
}

\author{
Ni Luh Putu Maykha Felycia ${ }^{1}$, Genoveva Genoveva ${ }^{2}$ \\ ${ }^{1,2}$ President University, Bekasi, Indonesia \\ Email korespondensi: ${ }^{2}$ genoveva@president.ac.id
}

\begin{abstract}
ABSTRAK
Penelitian ini bertujuan menganalisis keputusan pembelian konsumen di ritel tradisional dengan adanya pertumbuhan ritel modern yang terus meningkat, berdasarkan faktor-faktor lokasi, kenyamanan belanja, dan persepsi belanja masyarakat pada ritel tradisional dengan adanya pertumbuhan ritel modern yang terus meningkat. Jenis penelitian adalah penelitian kuantitatif. Data penelitian berupa data primer yang diperoleh melalui penyebaran kuesioner. Pemilihan sampel menggunakan metode judgement sampling, yaitu para responden dipilih dengan alasan tertentu, yaitu para pedagang toko tradisional dan masyarakat sekitar. Metode analisis data menggunakan structural equation model dengan Smart-PLS. Hasil penelitian menunjukkan bahwa lokasi tidak memiliki pengaruh signifikan terhadap keputusan pembelian pada ritel tradisional, kenyamanan belanja dan persepsi belanja memiliki pengaruh signifikan terhadap keputusan pembelian pada ritel tradisional. Implikasi hasil penelitian ini terhadap ritel tradisional agar dapat bersaing adalah memperhatikan kenyamaan berbelanja, sehingga peningkatan fasilitas seperti penggunan pendingin ruangan, dekorasi, dan pelayanan yang lebih baik adalah sangat penting.
\end{abstract}

Kata kunci: kenyamanan belanja; keputusan pembelian; persepsi belanja; ritel

\begin{abstract}
This study aims to analyze consumer purchasing decisions in traditional retail in the presence of modern retail growth continues to increase, based on location factors, shopping convenience, and people's perceptions of shopping at traditional retail with the increasing growth of modern retail. This type of research is quantitative research. Research data in the form of primary data obtained through the distribution of questionnaires. The sample selection used judgment sampling method, where the respondents were selected for certain reasons, namely the traditional shop traders and the surrounding community. The data analysis method uses a structural equation model with Smart PLS. The results showed that location did not have a significant effect on purchasing decisions at traditional retail, shopping convenience and shopping perceptions had a significant influence on purchasing decisions at traditional retail. The implication of the results of this study for traditional retailers to be able to compete is to pay attention to the convenience of shopping, so that improving facilities such as the use of air conditioning, decoration and better service is very important.
\end{abstract}

\section{Keywords: buying perception; purchasing decisions; retail; shopping convenience}

\section{KETERANGAN ARTIKEL}

Riwayat Artikel: diterima: 29 Juni 2021; direvisi: 29 November 2021; disetujui: 21 Desember 2021

Klasifikasi JEL: L81

Cara mensitasi: Felycia, N. L. P. M., \& Genoveva. (2021). Analisis Keputusan Pembelian Konsumen di Toko Tradisional dalam Menghadapi Pertumbuhan Ritel Modern. JIMFE (Jurnal Ilmiah Manajemen Fakultas Ekonomi), 7(2), 141-152. https://doi.org/10.34203/jimfe.v7i2.3540 


\section{PENDAHULUAN}

Kegiatan ritel di Indonesia terbagi menjadi dua, yaitu ritel modern dan ritel tradisional. Perbedaan antara ritel modern dan tradisonal dapat ditinjau dari beberapa aspek. Ritel modern memiliki keunggulan bersaing dalam hal, keadaan fisik yang baik dan cenderung mewah, metode penetapan harga yang pasti, memiki modal yang kuat, memerlukan tenaga kerja yang cukup banyak dan sistem pembayaran yang dibangun mengikuti teknologi yang berkembang (Child dkk., 2015; Nsimbi dkk., 2015). Karateristik ritel tradisional memiliki keadaan fisik yang kurang baik, penataan yang kurang rapih, metode penetapan harga yang dapat ditawar, memiliki modal lemah, dan pada umumnya menggunakan sistem pembayaran tunai (Utomo, 2011; Muqit, 2020).

Pertumbuhan ritel modern memiliki dampak yang sangat baik bagi kelangsungan ekonomi yang berada di sekitar ritel modern tersebut, namun terlepas dari itu ritel modern juga mempengaruhi kelangsungan dari ritel tradisional (Yulita, dkk., 2019). Menurut Aslam (2017) berbelanja di Hypermart, supermarket ataupun minimarket semakin menjadi trend seiring dengan berubahnya gaya hidup, orientasi dan pendapatan masyarakat. Dulu, banyaknya konsumen yang selalu mengejar harga murah, namun dengan meningkatnya kemajuan perekonomian di masing-masing daerah. Kenyamanan dalam berbelanja menjadi daya tarik sendiri, hal ini menjadi salah satu faktor di mana masyarakat lebih memilih berbelanja di ritel modern dari pada tradisional. Federasi Organisasi Pedagang Pasar Indonesia (FOPPI) diseluruh Indonesia menyatakan terjadi penyusutan jumlah ritel tradisional sebesar $8 \%$ pertahun. Ketidakjelasan mengenai industri ritel, salah satunya menyangkut jarak antara lokasi penyebaran usaha ritel baik modern maupun tradisional (Kuraesin \& Prasetyowati, 2018).

Dengan maraknya ekspansi yang dilakukan ritel-ritel modern yang mendapatkan keuntungan dari omzet yang terus meningkat di tiap tahunya artinya kemungkinan eskpansi tersebut akan terus berlanjut yang menyebabkan tingginya tingkat persaingan antarritel modern dan ritel tradisional (Colombo \& Hou, 2021). Pesatnya pertumbuhan ritel modern di Indonesia menyebar di seluruh wilayah, salah satunya Kabupaten Bekasi, Jawa Barat. Berdasarkan data Badan Pusat Statistik Provinsi Jawa Barat memiliki Pendapatan Domestik Regional Bruto (PDRB) yang cukup tinggi yaitu Rp1.491.705.807,48 sedangkan untuk Kabupaten Bekasi sendiri ada di angka Rp69.404.619.53. Hal ini tentunya didapatkan dari salah satu sektor perdagangan besar dan eceran dan berdampak positif bagi perekonomian daerah (Badan Pusat Statistik Provinsi Jawa Barat, 2017).

Menurut survei yang telah dilakukan oleh penulis di sekitar wilayah Desa Mekarmukti Kecamatan Cikarang Utara Kabupaten Bekasi didapatkan bahwa terdapat $60 \%$ ritel tradisonal telah melakukan penutupan retailnya, sedangkan untuk sebagian ritel yang masih beroprasi mengatakan bahwa mereka mengalami penurunan pendapatan dan jumlah masyarakat yang berbelanja. Berdasarkan wawancara dengan salah satu pemilik retail tradisional yang ada di sana, Budianto mengatakan hal ini tentunya dapat mempengaruhi kelangsungan usaha dari toko tradisional tersebut. Perilaku berbelanja konsumen berubah seiring dengan adanya tuntutan era modernisasi. Dalam tren perilaku konsumen pada era modern ini untuk pemilihan tempat belanja di Indonesia mengalami peningkatan, para konsumen sekarang menuntut kenyamanan dalam berbelanja (Azmi \& Genoveva, 2021). Hal yang membuat konsumen berpindah tempat belanja dari ritel tradisional ke ritel modern, salah satunya pelayanan (Aleksandra, 2021) dan lokasi (Colombo \& Hou, 2021). Perbedaan ini juga dapat dilihat dari lingkungan fisik, ritel modern cenderung memiliki ruang yang luas, ber-AC, lokasi yang mudah terjangkau, serta dibuka sepanjang hari sehingga konsumen akan lebih nyaman ketika berbelanja berbeda dengan konsep dari ritel tradisional konsumen yang datang biasanya hanya orientasi jangka pendek. Selain perubahan itu, perilaku konsumen yang terjadi karna adanya perhatian khusus konsumen terhadap kualitas produk yang akan dibeli, kepraktisan berbelanja seluruh kebutuhan di satu atap, kepastian suatu harga, kelengkapan produk ataupun fasilitas, dan mencari kebebasan memilih produk. 
Dalam memilih antara toko ritel modern dan toko ritel tradisional, konsumen memiliki beberapa evaluasi, seperti jarak, lokasi, kelengkapan produk, kualitas produk, pelayanan, dan kenyamanan berbelanja (Hanaysha, 2018; Aleksandra, 2021; Colombo \& Hou, 2021). Keputusan pembelian konsumen merupakan sikap yang dilakukan dalam memlih suatu produk untuk dikonsumsinya sebagai kebutuhan sehari-hari, tentunya konsumen memiliki kebebasan di mana mereka akan berbelanja sesuai dengan minat dan kebutuhan. Ritel modern dilihat dari pengelolaannya memiliki faktor yang hampir mendekati dengan keputusan pembelian konsumen yang membuat masyarakat tentunya banyak memilih berbelanja di ritel modern terdekat (Colombo \& Hou, 2021).

Penelitian sebelumnya memfokuskan pada pengaruh lokasi, minat belanja, dan pengaruh bauran pemasaran pada beberapa kota di Indonesia seperti Malang, Jember, Makassar, dan luar negeri seperti di Malaysia, Jerman dan Argentina, sedangkan penelitian ini berlokasi di Cikarang dan menggunakan satu variabel yang berbeda. Variabel berbeda yang kami gunakan adalah persepsi belanja. Selain itu, penelitian ini menggunakan kuesioner dan wawancara, sehingga data didapatkan dari dua belah pihak, yaitu responden dan pengelola ritel tradisional. Dari keseluruhan masalah yang telah dijabarkan di atas, penulis ingin mengetahui lebih jauh bagaimana pengaruh lokasi terhadap keputusan pembelian konsumen di ritel tradisional, lalu bagimana pengaruh kenyamanan belanja terhadap keputusan pembelian konsumen di ritel tradisional, serta bagaimana pengaruh persepsi belanja terhadap keputusan pembelian kosumen di ritel tradisional dengan bertumbuhnya ritel modern di wilayah Desa Mekarmukti Kecamatan Cikarang Utara Kabupaten Bekasi.

\section{KAJIAN LITERATUR DAN PENGEMBANGAN HIPOTESIS}

Lokasi

Dalam pertumbuhannya, ritel modern tentu sangat mempengaruhi kelangsungan ritel tradisional yang juga dapat dilihat dari lokasi yang begitu berdekatan. Menurut Indarti (2004) penentuan lokasi yang strategis akan menjadi jalan pembuka yang menentukan kesuksesan suatu usaha ritel. Saxena \& Hashemi (2011) lokasi ritel menjadi salah satu elemen penting dalam bisnis ritel, kemudahan akses akan meningkatkan konsumen yang datang dan meningkatkan penjualan secara signifikan, karena hal tersebut merupakan keputusan jangka panjang yang terkait dengan modal jangka panjang.

Keterjangkauan lokasi, kelancaran akses menuju lokasi, kedekatan lokasi (jarak), jadi lokasi suatu ritel akan menjadi keputusan strategis jangka panjang dalam kelangsungan usahanya dan menjadi salah satu kunci kesuksekan usaha suatu ritel. Selain menguntungkan konsumen, dari aspek pemilik bisnis, lokasi yang strategis memudahkan distribusi barang, karena menyangkut kemudahan akses, kecepatan perjalanan dan penghematan biaya distribusi. Berdasarkan paparan di atas, dapat disimpulkan bahwa lokasi mempengaruhi keputusan pembelian konsumen (Saxena \& Hashemi, 2011; Erkin, Dugundji, Koole, Gromicho, \& Mei, 2019; Soegiarto \& Masreviastuti, 2019).

\section{$\mathrm{H}_{1}$ : lokasi berpengaruh secara positif dan signifikan terhadap keputusan pembelian konsumen}

\section{Kenyamanan Belanja}

Kenyamanan berbelanja adalah sutu pengalaman yang menyenangkan bagi konsumen selama proses berbelanja, sehingga konsumen merasa senang dan ada kecenderungan melakukan penbelanjaan berikutnya (Mahkota, Suyadi, \& Riyadi, 2014). kondisi nyaman berbeda-beda pada setiap individu, sehingga kenyamanan bersifat subjektif. Gerai kecil yang tersusun rapih dan menarik akan lebih menarik perhatian konsumen dengan suasana yang didesain seindah mungkin akan membuat konsumen merasa nyaman dan betah berada disuatu gerai tersebut.

Kenyaman berbelanja mempengaruhi minat belanja, sehingga sangat penting untuk menghindari antian panjang, terbebas dari kemacetan lalulintas atau kesulitan mencari tempat parkir, sehingga 
menghabiskan waktu selama berbelanja sangatlah mempengaruhi minat belanja konsumen (Insani, 2013). Kenyamanan berbelanja dapat dilakukan dengan menciptakan dekorasi depan toko yang menarik, mendesain ritel secara kreatif dan menciptakan interior yang dapat menarik pengunjung berbelanja (Makaram \& Sarah, 2016). Berdasarkan penelitian Pusakanigwati \& Munir (2020) dapat disimpulkan bahwa kenyamanan belanja mempengaruhi keputusan pembelian di ritel. Hal yang senada diungkapkan juga dari hasil penelitian Rosita (2016), Soegiarto \& Masreviastuti (2019) yang menyimpulkan bahwa kenyamanan berbelanja berpengaruh terhadap keputusan pembelian ulang.

$\mathbf{H}_{2}$ : kenyamanan belanja berpengaruh positif dan signifikan terhadap keputusan pembelian konsumen

\section{Persepsi Belanja}

Pengambilan keputusan konsumen sangat dipengaruhi oleh faktor konsumen sebagai individu dan salah satunya tercakup pada proses persepsi. Proses persepsi merupakan bagaimana seseorang menginterpretasi dan menyerap mengenai suatu informasi yang didapat. Dengan kata lain, persepsi sesuatu yang bersal dari dua jenis faktor, yaitu: 1) stimulus factors, karakteristik secara fisik seperti bentuk, warna, ukuran dan berat. Tampilan yang baik akan menciptakan ransangan pada indera seseorang sehingga dapat menciptakan suatu nilai yang dilihat seseorang; 2) individual factors, karateristik yang tidak hanya terjadi pada indera tetapi bisa dengan pengalaman yang serupa dan dorongan utama dari individu itu sendiri (Fredereca \& Chairy, 2010; Dimyati, 2015).

Suatu persepsi konsumen dapat diartikan berbeda-beda meskipun keadaan yang sama. Hal ini dipengaruhi oleh berbagai faktor, antara lain 1) process perceptual, yaitu rangsangan sensorik, 2) atensi selektif, yaitu perhatian seseorang secara khusus terhadap suatu produk/jasa, 3) distorsi selektif adanya gangguan pada saat konsumen memperhatikan sesuatu secara khusus, dan 4) retensi selektif, yaitu pengulangan terhadap produk/jasa yang diminati (Kotler \& Amstrong, 2018).

Sciffman \& Kanuk (2014) persepsi merupakan rangkaian cara seseorang dalam memilih, mengatur, dan menafsirkan stimuli atau rangsangan. Persepsi juga memiliki implikasi strategis bagi pemasaran karena konsumen mengambil keputusan berdasarkan apa yang mereka rasakan. Berdasarkan konsep tersebut dapat disimpulkan persepsi seseorang berpengaruh dalam pengambilan keputusan pembelian. Hasil penelitian ini didukung oleh penelitian Aslam (2017) dan Pardede \& Haryadi (2017).

\section{$\mathrm{H}_{3}$ : persepsi belanja berpengaruh positif dan signifikan terhadap keputusan pembelian.}

Model penelitian yang kami gunakan dalam penelitian ini dapat digambarkan sebagai berikut.

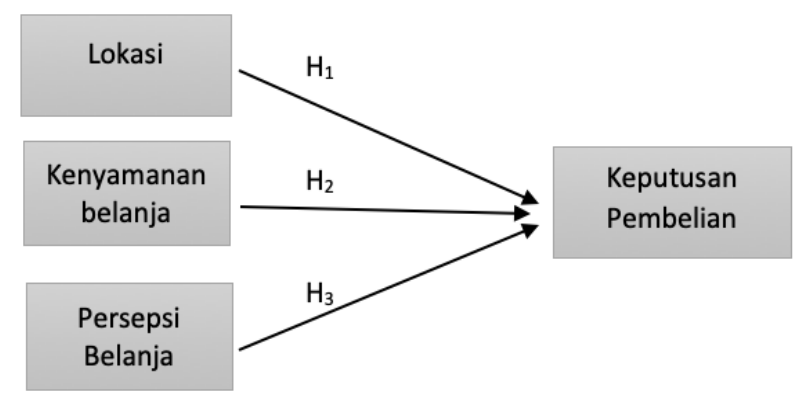

Gambar 1. Model Penelitian

\section{METODE PENELITIAN}

Penelitian ini adalah penelitian kuantitatif. Teknik pengambilan sampel menggunakan pendekatan nonprobablity sampling di mana setiap anggota populasi memiliki peluang yang sama, artinya bahwa pengambilan sample didasarkan pada criteria tertentu seperti status, kuantitas, kesukarelaan dan 
sebagainya. Penelitian ini menggunakan turunan dan variasi dari metode non-probablity sampling yaitu snowball sampling (Hair, Black, \& Anderson, 2010).

Penelitian ini didapatkan pada dua sumber data yaitu melalui wawancara dengan pemilik retail trasional dan kuesioner melalui konsumen. Kuesioner disebarkan terhadap 105 responden, tetapi kuesioner yang valid sebanyak 100 kuesioner, jumlah ini sudah sesuai dengan Hair, dkk. (2016) yang mensyaratkan bahwa jumlah responden adalah minimal lima kali jumlah indikator. Indikator dalam penelitian ini ada 20 pertanyaan, di mana setiap variabel memiliki lima pertanyaan. Penelitian ini menggunakan kuesioner sebagai alat pengumpulan data yang pokok. Berikut hasil penyebaran kuesioner yang dapat dilihat pada Tabel 1 sebagai berikut.

Tabel 1. Tingkat Pengembalian Kuesioner

\begin{tabular}{lc}
\hline Kuesioner yang disebar & 105 \\
\hline Kuesioner yang kembali & 100 \\
\hline Kuesioner yang diisi tidak lengkap & 5 \\
\hline Kuesioner yang dapat diolah & 100 \\
\hline
\end{tabular}

Penelitian ini memiliki tiga variabel independen dan satu variabel dependen. Lokasi sebagai variabel independen pertama $\left(\mathrm{X}_{1}\right)$ dengan indikator variabel keterjangkauan lokasi, akses lokasi, jarak antar ritel tradisional \& ritel modern, lokasi pesaing. Lalu kenyamanan belanja sebagai variabel independen kedua $\left(\mathrm{X}_{2}\right)$ dengan indikator variabel suasana ruangan, fasilitas ruangan, penempatan rak yang tersususn rapi. penataan barang/produk, kelengkapan produk, variasi produk, pelayanan, keamanan. Persepsi belanja sebagai variabel independen ketiga $\left(X_{3}\right)$ dengan indikator variabel gaya hidup, orientasi berfikir jangka panjang, orientasi berfikir jangka pendek, Harga, dan kepercayaan, sedangkan untuk variabel dependen atau variabel terikat yaitu keputusan pembelian konsumen di ritel tradisional sebagai variabel dependen $(\mathrm{Y})$ dengan indikator variabel prioritas pembelian pada produk tertentu, mencari informasi, mengevaluasi terhadap produk dan merekomendasikan kepada orang lain setelah melakukan pembelian. Teknik analisis data digunakan untuk menjawab rumusan masalah atau menguji hipotesis. Pengolaan data dalam penelitian ini menggunakan structural equation model. Dengan menggunakan dua tahap pengujian, yaitu analisa outer model dan inner model (Hair, Hult, G. T. M., Ringle, C. M., \& Sarstedt, 2016).

\section{HASIL DAN PEMBAHASAN}

\section{Uji Validitas}

Dalam penelitian ini, penulis menggunakan pendapat dari Sugiyono (2018) di mana jika nilai outer loading 0,500 sampai 0,600 dapat diterima atau bisa dikatakan variabel tersebut bisa diuji. Berdasarkan Tabel 2 di bawah ditemukan satu indikator variabel yang mempunyai nilai outer loading $<0,500$ maka indikator tersebut harus dieliminasi karena tidak memenuhi syarat. Pada uji yang telah dilakukan bahwa Indikator lokasi (LK4) kurang dari 0,50 maka indikator tersebut harus dieliminasi. Indikator kenyamanan belanja (KB5) nilai konstruknya lebih kecil maka harus dieliminasi. Berikut uji validitas cross loading pada Tabel 2. 
Ni Luh Putu Maykha Felycia: Analisis Keputusan Pembelian ...

Tabel 2. Uji Validitas Cross Loading

\begin{tabular}{ccccc}
\hline Indikator & $\begin{array}{c}\text { Kenyamanan } \\
\text { Belanja (KB) }\end{array}$ & Lokasi (LK) & $\begin{array}{c}\text { Persepsi Belanja } \\
\text { (PB) }\end{array}$ & $\begin{array}{c}\text { Keputusan } \\
\text { Pembelian (KPM) }\end{array}$ \\
\hline KB1 & 0,738 & 0,437 & 0,637 & 0,561 \\
KB2 & 0,731 & 0.429 & 0,583 & 0,479 \\
KB3 & 0,774 & 0,389 & 0,617 & 0,602 \\
KB4 & 0,758 & 0,379 & 0,646 & 0,527 \\
KB5 & 0,695 & 0,267 & 0,583 & 0,512 \\
KB6 & 0,804 & 0.480 & 0,677 & 0,546 \\
KB7 & 0,753 & 0,383 & 0,580 & 0,562 \\
KB8 & 0,782 & 0,440 & 0,561 & 0,533 \\
KPM1 & 0,630 & 0,423 & 0,719 & 0,820 \\
KPM2 & 0.670 & 0,395 & 0,741 & 0,867 \\
KPM3 & 0,571 & 0,404 & 0,566 & 0,778 \\
KPM4 & 0,578 & 0,443 & 0,639 & 0,822 \\
KPM5 & 0.449 & 0,346 & 0,564 & 0,772 \\
LK1 & 0.359 & 0,836 & 0,480 & 0,377 \\
LK2 & 0,422 & 0,847 & 0,465 & 0,375 \\
LK3 & 0,462 & 0,676 & 0,443 & 0,410 \\
PB1 & 0,456 & 0,553 & 0,703 & 0,507 \\
PB2 & 0,634 & 0,473 & 0,832 & 0,664 \\
PB3 & 0,765 & 0,472 & 0,852 & 0,652 \\
PB4 & 0,748 & 0,479 & 0,771 & 0,626 \\
PB5 & 0,646 & 0,444 & 0,869 & 0,759 \\
\hline
\end{tabular}

Berikutnya adalah pengujian nilai average variance extracted (AVE) dengan kriteria nilai $>0,500$ digunakan sebagai penentu validitas konvergen. Jika $<0,500$ maka tidak valid secara konvergen.

Tabel 3. AVE

\begin{tabular}{lccc}
\hline \multicolumn{1}{c}{ Variabel } & AVE Value & $\begin{array}{c}\text { Average Variance } \\
\text { Extracted }\end{array}$ & Keterangan \\
\hline Kenyamanan Belanja & $>0,500$ & 0,592 & Valid \\
Lokasi & $>0,500$ & 0,624 & Valid \\
Persepsi Belanja & $>0,500$ & 0,653 & Valid \\
Keputusan Pembelian & $>0,500$ & 0,660 & Valid \\
\hline
\end{tabular}

\section{Hasil Uji Reabilitas}

Suatu variabel dikatakan memiliki reabilitas yang tinggi maka nilai composite reability yang dimiliki harus $>0,700$. Dari Tabel 4 di bawah dapat dilihat bahwa seluruh nilai composite reability pada semua variabel memiliki nilai di atas 0,70 maka dapat dikatan bahwa semua variabel realibel dan tidak ada masalah pada uji composite reability. 
Tabel 4. Uji Reabilitas Composite Reability

\begin{tabular}{lccc}
\hline \multicolumn{1}{c}{ Variabel } & $\begin{array}{c}\text { Composite } \\
\text { Reliability Value }\end{array}$ & $\begin{array}{c}\text { Composite } \\
\text { Reliability }\end{array}$ & Keterangan \\
\hline Kenyamanan belanja & $>0,7$ & 0,910 & Reliable \\
\hline Lokasi & $>0,7$ & 0,831 & Reliable \\
\hline Persepsi belanja & $>0,7$ & 0,903 & Reliable \\
\hline $\begin{array}{l}\text { Keputusan pembelian } \\
\text { konsumen di ritel tradisional }\end{array}$ & $>0,7$ & 0,906 & Reliable \\
\hline
\end{tabular}

\section{Evaluasi Model Struktural}

Pengujian R-Square ini dilakukan hanya untuk variabel dependen $(\mathrm{Y})$, yang bertujuan untuk mengukur seberapa jauh kemampuan model dalam menerangkan variasi variabel dependen. Berdasarkan Tabel 5 di bawah dapat diketahui besarnya nilai R-Square $\left(R^{2}\right)$ keputusan pembelian adalah sebesar 0,658. Dengan demikian ini menunjukkan pengaruh antara variabel lokasi, kenyamanan belanja, dan persepsi belanja sebesar $65,8 \%$ dan sisanya $34,2 \%$ dipengaruhi oleh faktor lainnya.

Tabel 5. R-Square

\begin{tabular}{ccc}
\hline & R-Square & R-Square Adjusted \\
\hline $\begin{array}{c}\text { Keputusan } \\
\text { Pembelian }(\mathrm{Y})\end{array}$ & 0,658 & 0,648 \\
\hline
\end{tabular}

Nilai koefisien analisis jalur (Path Coefficients) hasil yang dapat dilihat dari Tabel 6 di bawah ini, pada kolom original sample $(\mathrm{O})$ yang digunakan untuk mengetahui nilai dari koefisien jalur. Berdasarkan hasil yang didapat maka disimpulkan pengujian antara variabel lokasi terhadap keputusan pembelian konsumen di ritel tradisional menunjukkan hasil 0,012, variabel kenyamanan belanja terhadap keputusan pembelian konsumen di ritel modern meunjukkan hasil 0,196, dan variabel persepsi belanja menunjukkan hasil 0,638. Dengan demikian dapat ditarik kesimpulan bahwa variabel kenyamanan belanja dan persepsi belanja menunjukkan pengaruh positif terhadap keputusan pembelian, sedangkan variabel lokasi tidak memiliki pengaruh yang signifikan terhadap keputusan pembelian konsumen di ritel tradisional.

Tabel 6. Nilai Koefisien Analisis Jalur (Path Coefficients)

\begin{tabular}{lccccc}
\hline & $\begin{array}{c}\text { Original } \\
\text { Sample } \\
(\mathbf{O})\end{array}$ & $\begin{array}{c}\text { Sample } \\
\text { Mean } \\
\text { (M) }\end{array}$ & $\begin{array}{c}\text { Standar } \\
\text { Deviasi } \\
\text { (STDEV) }\end{array}$ & $\begin{array}{c}\text { T Statistik } \\
(\mid \text { O/STDEV|) }\end{array}$ & P Values \\
\hline $\begin{array}{l}\text { Lokasi } \rightarrow \text { Keputusan } \\
\begin{array}{l}\text { Pembelian } \\
\text { Kenyamanan Belanja } \rightarrow\end{array}\end{array}$ & 0,012 & 0,018 & 0,076 & 0,154 & 0,878 \\
$\begin{array}{l}\text { Keputusan Pembelian } \\
\text { Persepsi Belanja } \rightarrow\end{array}$ & 0,196 & 0,189 & 0,098 & 1,998 & 0,046 \\
Keputusan Pembelian & 0,638 & 0,649 & 0,102 & 6,240 & 0,000 \\
\hline
\end{tabular}

Jika suatu variabel memiliki hasil nilai T-Statistik > 1,96 maka bisa dikatakan uji t pada variabel tersebut menerima Ha dan menolak Ho begitupun sebaliknya. Berikut hasil T-statistik yang didapat dalah pengolahan data pada Tabel 7 di bawah ini. 
Ni Luh Putu Maykha Felycia: Analisis Keputusan Pembelian ...

Tabel 7. Uji T-Statistik

\begin{tabular}{lcccccc}
\hline & $\begin{array}{c}\text { T- } \\
\text { Value }\end{array}$ & $\begin{array}{c}\text { T Statistik } \\
(\mid \mathbf{O} / \text { STDEV } \mid)\end{array}$ & $\begin{array}{c}\text { P } \\
\text { Values }\end{array}$ & Hasil & H01 & Ha1 \\
\hline $\begin{array}{l}\text { Lokasi } \rightarrow \text { Keputusan } \\
\text { pembelian }\end{array}$ & 1,960 & 0,154 & 0,878 & $\begin{array}{c}\text { Tidak } \\
\text { Signifikan }\end{array}$ & Diterima & $\begin{array}{c}\text { Tidak } \\
\text { Diterima }\end{array}$ \\
\hline $\begin{array}{l}\text { Kenyamanan belanja } \rightarrow \\
\text { Keputusan Pembelian }\end{array}$ & 1,960 & 1,998 & 0,046 & Signifikan & $\begin{array}{c}\text { Tidak } \\
\text { Diterima }\end{array}$ & Diterima \\
\hline $\begin{array}{l}\text { Persepsi belanja } \rightarrow \\
\text { Keputusan pembelian }\end{array}$ & 1,960 & 6,240 & 0,000 & Signifikan & $\begin{array}{c}\text { Tidak } \\
\text { Diterima }\end{array}$ & Diterima \\
\hline
\end{tabular}

Berdasarkan hasil analisis struktural model pada Tabel 7 di atas menunjukkan bahwa lokasi tidak memiliki pengaruh terhadap keputusan pembelian konsumen pada ritel tradisional dengan bertumbuhnya ritel modern. Hal ini ditunjukkan dengan nilai analisis path koefisien jalur antara variabel lokasi terhadap keputusan pembelian sebesar 0,012 dan uji t-hitung 0,154 $<1,96 \mathrm{t}$-tabel maka Ho di terima dan $\mathrm{H}_{1}$ ditolak. Nilai signifikan sebesar 0,878 $>0,05$ yang artinya lokasi tidak memilki pengaruh terhadap keputusan pembelian konsumen di ritel tradisonal dengan bertumbuhnya ritel modern. Hasil penelitian ini sejalan dengan penelitian yang sebelumnya dilakukan oleh Wijayanti (2013) dan Dialiwi (2017), di mana dalam penelitiannya menunjukkan bahwa lokasi tidak memiliki pengaruh terhadap keputusan pembelian. Hal ini didukung dengan hasil wawancara terhadap pemiik retail tradisional, di mana lokasi tidak begitu berpengaruh karena sudah menjamurnya retail, di mana retail modern bersanding dengan retail tradisional. Demikian juga dengan hasil kuesioner, lokasi tidak mempengaruhi keputusan pembelian konsumen. Keputusan para responden untuk memilih tempat belanja adalah sama rata dan dari keputusan pembelian tersebut tidak memiliki pengaruh yang banyak untuk kelangsungan suatu ritel tradisional.

Untuk variabel kedua menunjukkan bahwa kenyamanan belanja memiliki pengaruh yang signifikan terhadap keputusan pembelian konsumen di ritel tradisional dengan bertumbuhnya ritel modern. Hal ini ditunjukkan dengan nilai analisis path koefisien jalur antara variabel kenyamanan belanja terhadap keputusan pembelian sebesar 0,196 dan uji t-hitung 1,998 $>1,960 \mathrm{t}$-tabel maka $\mathrm{H}_{2}$ diterima dan Ho ditolak. Nilai signifikan sebesar 0,046 $<0,050$ yang artinya kenyamanan belanja berpengaruh positif dan signifikan terhadap keputusan pembelian konsumen di ritel tradisonal dengan bertumbuhnya ritel modern. Hasil penelitian ini sejalan dengan penelitian yang telah dilakukan Insani (2013), Makaram \& Sarah (2016), Pusakanigwati \& Munir (2020) di mana dalam penelitian mereka disimpulkan bahwa kenyamanan belanja berpengaruh positif terhadap keputusan pembelian. Kenyamanan belanja secara khusus memiliki tanggapan paling positif adalah mengenai tersedianya pendingin ruangan (AC) dan kemudahan mencari barang yang kan dibeli karena sudah ditata berdasarkan jenisnya. Demikian juga dengan hasil wawancara dengan pemilik retail tradisional, untuk dapat bersaing dengan retail modern, secara bertahap mereka meningkatkan kenyamanan belanja dengan melakukan renovasi secara bertahap terhadap tokonya, sehingga nampak lebih modern dan dapat bersaing.

Untuk variabel ketiga menunjukkan bahwa persepsi belanja memiliki pengaruh terhadap keputusan pembelian di ritel tradisional dengan bertumbuhnya ritel modern. Hal ini ditunjukkan dengan nilai analisis path koefisien jalur antara variabel kenyamanan belanja terhadap keputusan pembelian sebesar 0,638 dan uji t-hitung 6,240 > 1,960 t-tabel maka $\mathrm{H}_{2}$ diterima dan Ho ditolak. Nilai signifikan sebesar $0,000<0,050$ yang artinya persepsi belanja berpengaruh positif terhadap keputusan pembelian di ritel tradisonal/ritel modern. Hasil penelitian ini sejalan dengan penelitian yang telah dilakukan di 
mana dalam penelitian Dimyati (2015), Aslam (2017), Pardede \& Haryadi (2017) persepsi belanja memiliki pengaruh positif terhadap keputusan pembelian. Persepsi yang diinginkan oleh responden adalah harga yang bersaing dan adanya promosi penjualan di retail, sedangkan dari pemilik retail tradisional, mereka mencoba bersaing dengan memberikan pelayanan yang ramah.

\section{KESIMPULAN}

Dari hasil olah data yang telah dilakukan dapat ditarik kesimpulan bahwa lokasi tidak memiliki pengaruh signifikan terhadap keputusan pembelian konsumen pada ritel tradisional dengan bertumbuhnya ritel modern. Hal ini dikarenakan sudah banyaknya penyebaran ritel modern bahkan yang bersebelahan, baik dari sesama ritel modern/tradisional, yang sesuai dengan penyebaran hasil kuesioner dan pengamatan langsung pada kawasan tersebut, sehingga keputusan pembelian yang dilakukan oleh responden cenderung merata.

Kenyamanan belanja memiliki pengaruh yang signifikan terhadap keputusan pembelian konsumen pada ritel tradisional dengan bertumbuhnya ritel modern. Hal ini karena kenyamanan yang dirasakan responden ketika berbelanja di ritel modern lebih mendominasi sesuai dengan hasil penyebaran kuesioner yang telah dilakukan, bahwa dapat dikatakann ritel modern lebih unggul dalam kenyamanan belanja dibandingkan ritel tradisional. keputusan pembelian ini pun yang pada akhirnya akan berpengaruh terhadap keputusan pembelian konsumen pada ritel tradisional. Persepsi belanja memiliki pengaruh signifikan terhadap keputusan pembelian konsumen pada ritel tradisional dengan bertumbuhnya ritel modern. Hal ini dikarenakan persepsi belanja disetiap responden berbeda-beda dan dapat diukur melalui gaya hidup, orientasi berfikir, penentuan harga, dan kepercayaan di mana dari hasil penyebaran kuesioner dan pengamatan yang dilakukan dikawasan tersebut responden banyak yang berbelanja di ritel modern untuk memenuhi kebutuhan bulanan dan bakan terkadang berbelanja di ritel modern untuk kebutuhan harian jika pada ritel tradisional tidak ada barang yang dibutuhkan.

Implikasi manajemen bagi pengelola ritel tradisional adalah harus lebih memperhatikan kenyamanan belanja seperti penyediaan pendingin ruangan dan kemudahan mencari barang. Selain itu ketersedian produk, pertimbangan harga, mengecek tanggal kadaluarsa disetiap produk adalah hal-hal yang harus menjadi perhatian. Hal ini dapat meningkatkan dan mempertahankan kepercayaan para pembeli yang nantinya akan menjadi pilihan utama seorang pembeli melakukan keputusan pembelian. Implikasi bagi pemerintah, perlu dibuat kebijakan yang membatasi jumlah ritel modern, dengan memperhatikan jarak antar ritel dan memperhitungkan jumlah penduduk di suatu kecamatan. Saran bagi para pembaca dan penelitu selanjutnya dianjurkan menggunakan data yang lebih luas agar mendapatkan hasil yang lebih akurat, misalnya dengan memperluas daerah peneliatian dan menambah jumlah variabel bebas sehingga sample yang diperoleh pun banyak karna dengan menggunkan sample yang lebih banyak akan lebih menggambarkan keputusan pembelian pada ritel tradisional dengan bertumbuhnya ritel modern.

\section{DAFTAR PUSTAKA}

Aleksandra, V. (2021). Retail Enterprise Management. Journal of Economics, Trade and Marketing Management, 3(1), 11-19.

Aslam, A. (2017). Pengaruh Pertumbuhan Minimarket Terhadap Minat Dan Kebiasaan Belanja Masyarakat Di Kelurahan Tamamaung Kota Makassar. Universitas Islam Negeri Alauddin.

Azmi, A. \& Genoveva, G. (2021). The Change of Indonesians Lifestyle Towards Food Purchase Decision During Covud-19 Pandemic (Paper Presentation). ICFBE (International Conference of Family Business \& Entrepreneurship) 4(226-237). 
Badan Pusat Statistik Provinsi Jawa Barat. (2017). Provinsi Jawa Barat dalam Angka 2017. https://jabar.bps.go.id/publication/2017/08/12/62379e17bcc20052a7991d35/provinsi-jawabarat-dalam-angka-2017.html

Child, P., Kilroy, T., \& Naylor, J. (2015). Modern Grocery And The Emerging-Market Consumer: A Complicated Courtship. Hongkong, Chicago \& London: McKensey \& Company.

Colombo, S., \& Hou, Z. (2021). Location-Price Equilibria when Tranditional Retailers Compete Against an Online Retailer. Review of Industrial Organization, 59, 483-502.

Dimyati, M. (2015). Persepsi Konsumen Terhadap Bauran Ritel Tradisional dan Modern di Kota Jember. Jurnal IImiah RELASI, 11(2), 175-196.

Erkin, D., Dugundji, E. R., Koole, G., Gromicho, J., \& Mei, R. V. (2019). Buffering Locations in Retail Deliveries. Procedia Computer Science, 152, 116-123.

Fredereca, B., \& Chairy, C. (2010). Pengaruh Psiologi Konsumen Terhadap Keputusan Pembelian Kembali Smartphone Blackberry. Jurnal Manajemen Teori dan Terapan, 3(2), 128-143.

Hair, J. F., Hult, G. T. M., G. T., Ringle, C. M., C. M., \& Sarstedt, M. (2016). A Primer on Partial Least Squares Structural Equation Modeling (PLS-SEM). Thousand Oaks: SAGE Publications, Inc.

Hair, J., Black, B. J., \& Anderson, R. E. (2010). Multivariate Data Analysis (Vol. Seventh Editioon). New Jersey: Prentice Hall.

Hanaysha, J. (2018). An examination of the factors affecting consumer's purchase decision in the Malaysian retail market. PSU Resegrch Review, 2(1), 7-23.

Indarti, N. (2004). Business Location and Success: The Case of Internet Cafe Business in Indonesia. Gadjah Mada Interntional JOurnal of Business, 6(2), 171-192.

Insani, E. (2013). Analisis Pengaruh Kenyamanan Terhadap Minat Beli Secara Online Pada Pemesanan Tiket Kereta Api Melalui Websute Resmi PT KAI. Jurnal Sains Pemasaran Indonesia, 12(3), 241250.

Kotler, P., \& Amstrong, G. (2018). Principles of Marketing (Vol. Seventeenth edition). Pearson Higher Education: Hoboken.

Kuraesin, E., \& Prasetyowati, R. A. (2018). Comparative Analysis Of Continuity of Modern Retail Minimarket And Traditional Retail Businesses In Indonesia. Inovator, 7(1), 35-68.

Maharani , A. R., \& Ari, D. (2014). Efek Mediasi Informasi Asimetris dan Moderasi Locus of Control pada Pengaruh Partisipasi Anggaran dan Penekanan Anggaran terhadap Budgetary Slack. Jurnal Akuntansi Multiparadigm, 13(2), 90-110.

Mahkota, A., Suyadi, I., \& Riyadi, R. (2014). Pengaruh Kepercayaan Dan Kenyamanan Terhadap Keputusan Pembelian Online. Jurnaal Administrsi Bisnis, 8(2), 1-7.

Makaram, \& Sarah, I. S. (2016). Analisis Faktor Lingungan Bisnis Ritel Berbasis Swalayan. Jurnal Bisnis dam Investasi, 2(3), 85-104.

Mc Dornot. (2014). The Politics Of Institutional Renovation And Economic Upgrading: Recombining The Vines That Bind In Argentina. Politics \& Society, 35(1), 103-144.

Muqit, A. (2020). Manajemen Ritel Strategi Untuk Keunggulan Bersaing. Malang: Polinema Press.

Nsimbi, C., Makgosa, R., Themba, G., \& Lyanda, O. (2015). Modern Retailing and its Implications for Developing Countries: Insights from Retail Managers. Journal Title Business Management and Strategy, 6(1), 1-24.

Pardede, R., \& Haryadi, T. Y. (2017). Pengaruh Persepsi Harga Dan Kualitas Produk Terhadap Keputusan Pembelian Konsumen Yang Dimediasi Kepuasan Konsumen. Journal of Business \& Applied Management, 10(1).

Pusakanigwati, A., \& Munir, M. (2020). Analisis Pengaruh Harga, Tata Letak, Kenyamanan Belanja, Kelengkapan Produk, Lokasi dan Pelayanan Terhadap Sikap Konsumen Dengan Pendekatan Regresi Linear Berganda. Journal Knowledge Industrial Engineering, 7(2), 70-79. 
Rosita, R. (2016). Pengaruh Lokasu, Kelengkapan Produk, Kualtas Produk, Pelayanan, Harga dan Kenyamanan Berbelanja Terhadap Minat Beli Ulang KOnsumen Pada Lotter Mart Bekasi Junction. Jurnal Olmiah Widaya Ekonomika, 1(2), 98-103.

Santo, A., \& Widowati, S. (2011). Pengaruh Kualitas Pleayanan, Fasilitas fan Lokasi Terhdap Keputusan Pembelian. Jurnal Dinamika Sosial Budaya, 1, 179-190.

Saxena, R., \& Hashemi, B. A. (2011). Importance of Location in Successful Retailing. The International Journal of Knowledge, Culture and Change Management, 11(1), 37-60.

Sciffman, L., \& Kanuk, L. (2014). Consumer Behavior (Vol. Eleventh Edition). New Jersey: Pearson.

Soegiarto, K., \& Masreviastuti. (2019). Pengaruh Store Atmosphere dan Lokasi Terhadap Keputusan Pembelian di Alfabeta Mart Malang. Jurnal Aplikasi Bisnis, 5(1), 89-92.

Sugiyono. (2018). Metode Penelitian Kuantitatif. Bandung: Alfabeta.

Utomo, T. (2011). Persaingan Bisnis Ritel: Tradisional Vs Modern (The Competition of Retail Business: Traditional vs Modern). Fokus Ekonomi, 6(1), 122-133.

Yulita, F., Simanjuntak, M., \& Sartono, B. (2019). Shopping Behavior of Indonesian Customer in Modern Retail. Russian Journal of Agricultural and Socio Economic Sciences, 95-101. 
